Short Communication

\title{
DNA sampling from eggshells and microsatellite genotyping in rare tropical birds: Case study on Brazilian Merganser
}

Thais Augusta Maia ${ }^{1}$, Sibelle Torres Vilaça ${ }^{2}$, Luciana Resende da Silva ${ }^{3}$, Fabricio Rodrigues Santos ${ }^{3}$ and Gisele Pires de Mendonça Dantas ${ }^{1}$

${ }^{1}$ Laboratório de Ecologia e Evolução de Aves, Programa de Pós-Graduação em Biologia de Vertebrados, Pontifícia Universidade Católica de Minas Gerais, Belo Horizonte, MG, Brazil.

${ }^{2}$ Department Evolutionary Genetics, Leibniz Institute for Zoo and Wildlife Research, and Berlin Center for Genomics in Biodiversity Research, Berlin, Germany.

${ }^{3}$ Laboratório de Biodiversidade e Evolução Molecular, Instituto de Ciências Biológicas, Universidade

Federal de Minas Gerais, Belo Horizonte, MG, Brazil.

\begin{abstract}
This study shows that sampling maternal DNA from hatched and abandoned eggshells is a viable noninvasive strategy for studying the genetics of rare or endangered tropical birds, as exemplified here by the Brazilian Merganser (Mergus octosetaceus). Eighteen microsatellites were isolated from enriched libraries and nine heterologous loci from related species were tested. Seven loci were amplified successfully, with five of them being polymorphic. These loci exhibited amplicons ranging from 110 to 254 bp for 132 samples, with 60 from eggshells and 72 from blood or muscle samples. The number of alleles for $M$. octosetaceus ranged from one to six (mean $=3.71$ ), which is low compared to $M$. merganser (1-15 alleles), a 'least concern' species. Genetic diversity did not differ significantly between noninvasive and invasive samples $(Z(u)=0.31, p=0.37)$. Thus, noninvasive sampling, as demonstrated here with eggshells, provides an efficient means to assess genetic diversity in tropical birds without the need to capture and handle them.
\end{abstract}

Keywords: DNA, noninvasive samples, genetic diversity, endangered birds, Mergus.

Received: October 31, 2016; Accepted: August 4, 2017.

Noninvasive DNA sampling has become an important method for collecting valuable genetic data for the management and conservation of rare and endangered species (Waits and Paetkau, 2005; Beja-Pereira et al., 2009; Egloff et al., 2009). For birds, the use of eggshells and feathers are good sources of biological samples (Pearce $e t$ al., 1997; Bush et al., 2005; Egloff et al., 2009). However, noninvasive sampling from tropical species is particularly challenging due to several environmental factors, including high temperatures, precipitation and UV radiation, which can promote DNA degradation (Brinkman et al., 2010; Vynne et al., 2012; Wultsch et al., 2014).

Some studies have used microsatellites for accessing genetic diversity from noninvasive samples (Presti et al., 2013; Moodley et al., 2015), due to the fact that these markers are widely distributed in the genome, have high levels of polymorphism, and are easy to detect using PCR (Hoshino et al., 2012). Thus, microsatellites have been frequently

Send correspondence to Gisele Pires Mendonça Dantas. Laboratório de Ecologia e Evolução de Aves, PUC Minas Gerais, Av. Dom Jose Gaspar, 500 Predio 41, Coração Eucaristico, 30535-901 Belo Horizonte, MG, Brazil. E-mail: giseledantas@pucminas.br. used to monitor biodiversity, evaluate paternity and to attribute individuals to populations (Beebee and Rowe, 2008). Furthermore, primers developed in one species may be used in related taxa (Barbará et al., 2007; Santos et al., 2012). Nonetheless the success of cross-species amplification of microsatellites depends on conservation of flanking regions, the polymorphism level, the phylogenetic relatedness among the species involved, with success being higher in closely related species (Barbará et al., 2007; Presti et al., 2013; Moodley et al., 2015). In this context, the use of noninvasive samples and polymorphic markers, such as microsatellites, can help to monitor the genetics of rare and endangered species.

The Brazilian Merganser (Mergus octosetaceus) is considered critically endangered, with a global population estimated to be less than 250 individuals, distributed among three or four disjointed populations located in protected areas of Brazil (BirdLife International, 2015). Until the moment, only one genetic study was conducted with this species, where two mitochondrial lineages were observed, with high divergence and low variability within each (Vilaça et al., 2012). Thus, questions were raised about the ge- 
netic diversity and evolutionary history of the Brazilian Merganser.

The present study aims to: 1) test a noninvasive method of sampling avian DNA from abandoned eggs and hatched eggshells, 2) develop new microsatellite markers for the Brazilian Merganser through sequencing of enriched libraries, and 3) test cross-amplification using previously described primers for other species of Anseriformes.

In total, 132 Brazilian Merganser samples were collected in the Serra da Canastra National Park over the course of eight years (2005-2013), including 59 blood tissue samples from captured individuals, 13 muscle samples from dead individuals, and 60 noninvasive samples from eggshells (membrane and shells) of abandoned or hatched eggs in nests. The nests were monitoring through the entire study period, adults were ringed and only one eggshell of each nest was used, trying to avoid resampling. The length of time that the eggshell was exposed to environmental conditions could not be determined. All samples were georeferenced, kept in plastic bags, and stored in a refrigerator for subsequent analysis. Genomic DNA was extracted from eggshell (shell and intern membrane), blood and muscle samples using the protocol described in Sambrook et al. (2001). They were treated with lysis solution (TrisHCl 0.1 $\mathrm{M}, \mathrm{pH}$ 8.0; EDTA 0.5 M; SDS 0.2\%; $\mathrm{NaCl} 1 \mathrm{M}$ ) containing proteinase $\mathrm{K}$, overnight at $37^{\circ} \mathrm{C}$, followed one wash with phenol:chloroform:isoamyl alcohol $(25: 24: 1)$ and one wash with chloroform:isoamyl alcohol (24:1), precipitation with isopropanol $100 \%$ and ethanol $70 \%$. The DNA concentration of all samples was quantified spectophotometrically using NanoDrop ND-1000 (Nanodrop, USA).

Microsatellite enriched libraries were constructed following the methodology described in Billotte et al. (1999), using streptavidin magnetic-coated beads (Promega, Madison, WI). DNA $(\sim 5 \mu \mathrm{g})$ extracted from one blood sample was digested with the enzyme RsaI to create an appropriately sized genomic library (400-1000 bp). The digested fragments were ligated to the adaptors RSA21 (5' CTCTTGCTTACGCGTGGACTA 3') and RSA25 (5' TAGTCCACGCGTAAGCAAGAGCACA 3'). The DNA library was enriched for dinucleotide sequences using $(\mathrm{CT})_{8}$ and $(\mathrm{GT})_{8}$ biotinylated probes that were bound to streptavidin magnetic-coated beads (Streptavidin MagneSphere Paramagnetic Particles, Promega). Selected fragments were amplified by PCR using primer sequences complementary to the RSA21 adapter and then cloned into the pGEM-T vector (Promega). Competent XL1-blue E. coli cells were transformed with the recombinant plasmids and cultivated on agar medium containing ampicillin and $100 \mu \mathrm{g} / \mathrm{mL}$ of X-galactosidase. Single white colonies were transferred onto microplates for long-term storage at -80 ${ }^{\circ} \mathrm{C}$. Ninety-six clones containing an insert were sequenced using a MEGABACE 1000 automated sequencer (GE Healthcare Life Sciences). Microsatellites were identified using the Simple Sequence Repeat Identification Tool (Temnykh et al., 2001).

Primers were designed for 18 loci containing microsatellites using Primer3Plus software (Untergasser et al., 2007). An M13 tail was added to the forward primer of each primer pair to allow fluorescent labeling during amplification reactions (Schuelke, 2000). In addition, we tested the cross-amplification of additional microsatellite loci using four primer pairs developed for M. merganser (Gautschi and Koller, 2005), four primer pairs developed for Anas platyrhynchus (Maak et al., 2003), and one primer pair developed for Anatidae (Buchholz et al., 1998) (Supplementary material Table $\mathrm{S} 1$ ).

PCR amplifications were performed in a $10 \mu \mathrm{L}$ reaction volume containing $25 \mathrm{ng}$ of genomic DNA, $0.7 \mu \mathrm{M}$ forward primer, $8 \mu \mathrm{M}$ reverse primer, $8 \mu \mathrm{M}$ M13tag marked with HEX or FAM, $250 \mu \mathrm{M}$ dNTPs, $0.5 \mathrm{U}$ Taq DNA polymerase (Lifetech Carlsbad, EUA) and $1 \mathrm{X}$ reaction buffer ( $20 \mathrm{mM}$ TrisCl, $0.1 \mathrm{mM}$ EDTA, $1 \mathrm{mM}$ DTT) with a final concentration of $2.5 \mathrm{mM} \mathrm{MgCl} 2$. We used a touchdown PCR program of $95^{\circ} \mathrm{C}$ for $15 \mathrm{~min}$, followed by 30 cycles at $94{ }^{\circ} \mathrm{C}$ for $30 \mathrm{~s}, 65^{\circ} \mathrm{C}$ for $30 \mathrm{~s}$, reducing $0.5^{\circ} \mathrm{C}$ per cycle, and $72^{\circ} \mathrm{C}$ for $1 \mathrm{~min}$. The next 20 cycles were 94 ${ }^{\circ} \mathrm{C}$ for $30 \mathrm{~s}, 48^{\circ} \mathrm{C}$ per $30 \mathrm{~s}$, and $72{ }^{\circ} \mathrm{C}$ for $1 \mathrm{~min}$. The last cycle was followed by a $30 \mathrm{~min}$ extension step at $72^{\circ} \mathrm{C}$. Two parameters were used to consider unsuccessful amplifications after several attempts at standardization: a locus did not amplify, or the locus showed unspecific bands. We tested each microsatellite locus with different PCR conditions that varied in concentrations of $\mathrm{MgCl}_{2}(1.0 \mathrm{mM}$ to 5.0 $\mathrm{mM}$ ), temperature gradient, and DNA concentration. The amplicons were diluted, mixed with internal size standard Rox500 (Applied Biosystems, Foster City, CA, USA), run on an ABI3130 instrument (Applied Biosystems), and analyzed using GeneMapper (Applied Biosystems). Genotyping of the samples was performed at least twice to confirm the amplicons. When the sample showed same genotype in two independent runs we considered this to the correct genotyping. When the sample showed distinct genotypes in two first runs we did another run (third run) and determined the genotype by consensus. The consensus decision was done by eye, and the error rate was very low $(<2 \%)$, with the genotyping confirmed either by the second or third run.

MICRO-CHECKER was used to evaluate dropout and null alleles in the invasive and noninvasive samples (Van Oosterhout et al., 2004). Loci linkage loci was test in GenePop (Raymond and Rousset, 1995). Allelic richness, expected and observed heterozygosity, exact tests for departure from Hardy-Weinberg equilibrium and coefficients of inbreeding (FIS) were determined using GeneAlEx v6.5 (Peakall and Smouse, 2012).

DNA was successfully extracted from eggshells exposed to environmental conditions before sampling, in spite of the DNA concentration of noninvasive samples being lower $(\sim 30 \mathrm{ng} / \mu \mathrm{l})$ than that of invasive samples (> 300 


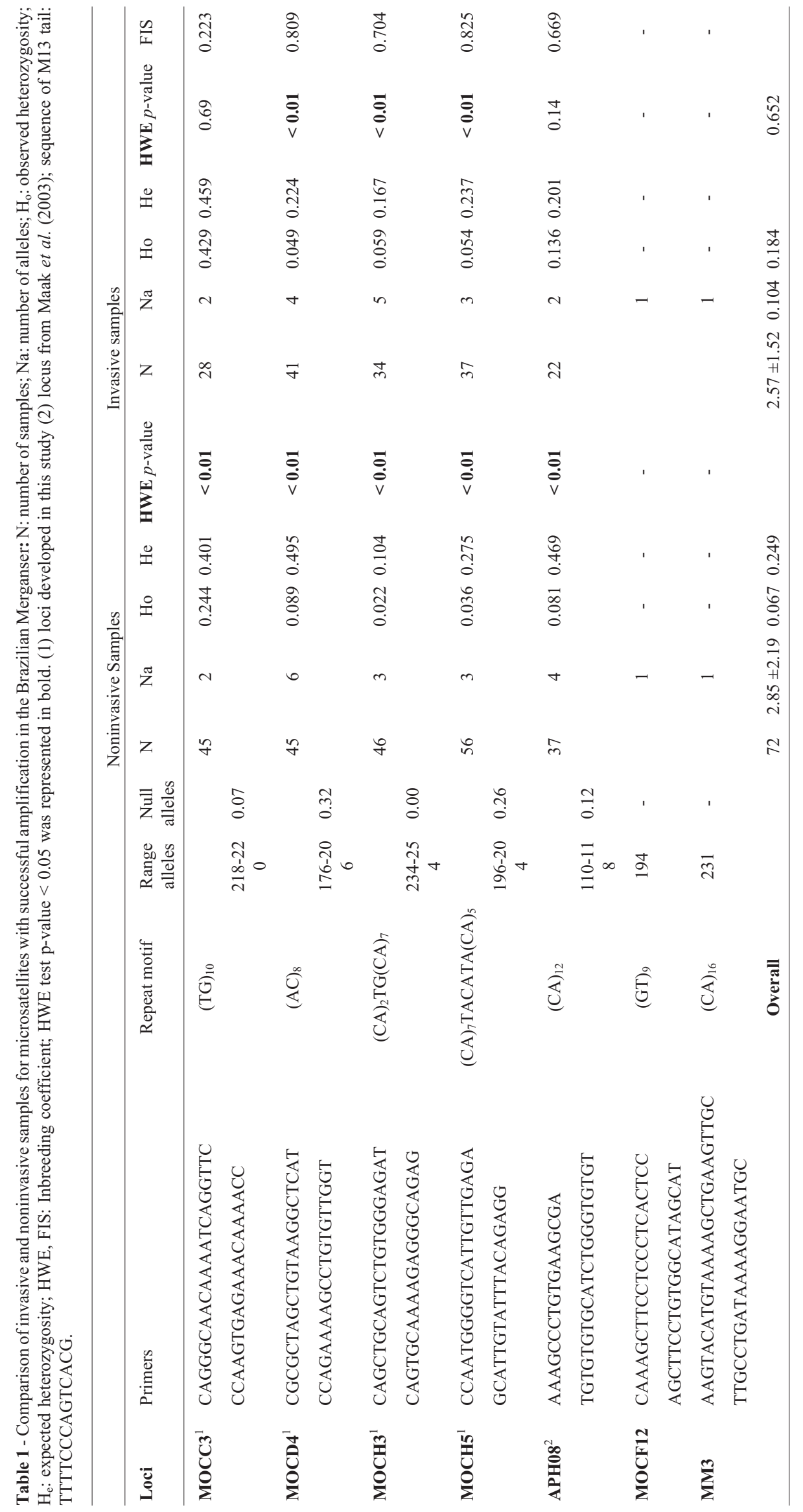


$\mathrm{ng} / \mu \mathrm{l})$. Most avian genetics studies that employ noninvasive sampling use feathers (Segelbacher, 2002; Presti et al., 2013), although a few have used eggshell membranes (Trimbos et al., 2009), eggshell powder by surface abrasion (Egloff et al., 2009), or eggshell swabbing (Martin-Galvez et al., 2011).

Of the 27 microsatellite loci tested (Table S1), amplification occurred in seven (MOCC3, MOCD4, MOCF12, MOCH3, MOCH5, Aph08, MM03), with amplicons ranging from 110 to $254 \mathrm{bp}$ (Table 1). MOCF12 (allele 194) and MM03 (allele 231) were found to be monomorphic. The loci Aph08 and MM03 were sequenced to confirm the microsatellites. In the pairwise locus analyses, none showed a linkage disequilibrium. Sixty-five percent of the invasive samples and 50 percent of the noninvasive samples were successfully amplified for seven loci, of which five exhibited polymorphisms with two to six alleles. Our results showed lower amplification success for heterologous markers $(22.2 \%)$ vs. species-specific loci $(27.7 \%)$. Mutations in flanking regions or disruptions within tandem-repeated elements may lead to failure of amplification and reduced levels of polymorphism in cross amplification (Moodley et al., 2015). Accordingly, only one heterologous marker showed success of amplification in Brazilian Merganser, therefore development of specific markers allowed access genetic diversity with success. These markers will allow to assess genetic diversity in wild populations and in distinct kinds of samples.

Previous studies with noninvasive samples found that these can result in low-quality DNA that may even be contaminated with PCR inhibitors (Horváth et al., 2005; Presti et al., 2013), thus hindering genotyping (Taberlet et al., 1996; Mukesh et al., 2011). We minimized the possibility of genotyping errors by running each sample at least twice and by testing the occurrence of allele dropout in MICROCHECKER. No sign of allele dropout was detected in any of the loci. However, it showed the possibility of null alleles for some loci (Table 1) due to an excess of homozygotes, where all loci from noninvasive samples showed an HWE bias, as well as three loci from invasive samples. This excess of homozygotes could also be consequence of inbreeding, given that the population is small and apparently isolated (FIS 0.66).

Genetic diversity (Table 1) did not differ significantly between invasive and noninvasive samples (MannWhitney $\mathrm{Z}(\mathrm{u})=0.31, \mathrm{p}=0.37)$, with mean allelic number $2.51( \pm 1.52)$ and $2.85( \pm 2.19)$, and observed heterozygosity of 0.067 and 0.104 for noninvasive and invasive samples, respectively (Table 1). The Brazilian Merganser showed low allelic richness ( 1 to 6 alleles; mean $=3.71$ ) when compared to its sister species, the least concern $M$. merganser (1 to 15 alleles per locus, mean $=6.88$ ); Gautschi and Koller 2005), with the caveat that the panel used in these studies did not include the same loci.
In conclusion, the results of the present study should encourage the practice of extracting maternal DNA from eggshells found in the field, even if deposited several days before sampling. However, the panel of microsatellite markers used in this study showed some limitations, such as low polymorphisms and successful of amplification in only about $50 \%$ of the samples. Despite these limitations, the microsatellites revealed low genetic diversity in the critically endangered Brazilian Merganser. Furthermore, these new markers should allow to assess the genetic diversity in other wild populations with higher samples size, and consequently will be of help in management and protection decisions.

\section{Acknowledgments}

This work was supported by FAPEMIG (Fundação de Amparo à Pesquisa do Estado de Minas Gerais), CNPq, CAPES (Coordenação de Aperfeiçoamento de Pessoal de Nível Superior), Petrobras, and Fundação de Boticário de Proteção à Natureza. We also thank Livia Lins from the Instituto Terra Brasilis for collecting samples. We thank Dr. John M. Pearce (Alaska Science Center, USGS) for kindly sending us the primers for the heterologous loci. We appreciate the improvements in English usage provided by Caitlin Stern through the Association of Field Ornithologists' program of editorial assistance. The study is in compliance with all current Brazilian laws.

\section{References}

Barbará T, Palma-Silva C, Paggi GM, Bered F, Fay MF and Lexer C (2007) Cross-species transfer of nuclear microsatellite markers: Potential and limitations. Mol Ecol 16:3759-3767.

Beebee T and Rowe G (2008) An Introduction to Molecular Ecology. Oxford Press, Oxford, $400 \mathrm{p}$.

Beja-Pereira A, Oliveira R, Alves PC, Schwartz MK and Luikart G (2009) Advancing ecological understandings through technological transformations in noninvasive genetics. Mol Ecol Resour 9:1279-1301.

Billotte N, Lagod PJL, Risterucci AM and Baurens FC (1999) Microsatellite-enriched libraries: Applied methodology for the development of SSR markers in tropical crops. Fruits 54:277-288.

Brinkman TJ, Schwartz MK, Person DK, Pilgrim KL and Hundertmark KJ (2010) Effects of time and rainfall on PCR success using DNA extracted from deer fecal pellets. Conserv Genet 11:1547-1552.

Buchholz WG, Pearce JM, Pierson BJ and Scribner KT (1998) Dinucleotide repeat polymorphisms in waterfowl (family Anatidae): Characterization of a sex-linked (Z-specific) and 14 autosomal loci. Anim Genet 29:323-325.

Bush KL, Vinsky MD, Aldridge CL and Paszkowski CA (2005) A comparison of sample types varying in invasiveness for use in DNA sex determination in an endangered population of greater Sage-Grouse (Centrocercus uropihasianus). Conserv Genet 6:867-870.

Egloff C, Labrosse A, Hebert C and Crump D (2009) A nondestructive method for obtaining maternal DNA from avian 
eggshells and its application to embryonic viability determination in herring gulls (Larus argentatus). Mol Ecol Resour 9:19-27.

Gautschi B and Koller B (2005) Polymorphic microsatellite markers for the goosander (Mergus merganser). Mol Ecol Notes 5:133-134.

Horváth MB, Martínez-Cruz B, Negro JJ, Kalmár L and Godoy JA (2005) An overlooked DNA source for non-invasive genetic analysis in birds. J Avian Biol 36:84-88.

Hoshino AA, Bravo JP, Nobile PM and Morelli KA (2012) Microsatellites as tools for genetic diversity analysis. In: Caliskan M (ed) Genetic Diversity in Microorganisms. InTech Open, Rijeka, pp 149-170.

Maak S, Wimmers K, Weigend S and Neumann K (2003) Isolation and characterization of 18 microsatellites in the Peking duck (Anas platyrhynchos) and their application in other waterfowl species. Mol Ecol Notes 3:224-227.

Martin-Galvez D, Peralta-Sanchez JM, Dawson DA, Martin-Platero AM, Martinez-Bueno M, Burke T and Soler JJ (2011) DNA sampling from eggshell swabbing is widely applicable in wild bird populations as demonstrated in 23 species. Mol Ecol Resour 11:481-493.

Moodley Y, Masello JF, Cole TL, Calderon L, Munimanda GK, Thali MR, Alderman R, Cuthbert RJ, Marin M, Massaro M, et al. (2015) Evolutionary factors affecting the cross-species utility of newly developed microsatellite markers in seabirds. Mol Ecol Resour 15:1046-1058.

Mukesh M, Mandhan R and Sathyakumar S (2011) Comparison of different parameters of invasive and noninvasive sampling methods for microsatellite genotyping: A casestudy from Red Junglefowl and its application for other Galliformes. J Res Biol 1:38-43.

Peakall R and Smouse PE (2012) GenAlEx 6.5: Genetic Analysis in Excel. Population genetic software for teaching and research - An update. Bioinformatics 28:2537-2539.

Pearce JM, Fields RL and Scribner KT (1997) Nest materials as a source of genetic data for avian ecological studies. J Field Ornithol 68:471-481.

Presti FT, Meyer J, Antas PTZ, Guedes NMR and Miyaki CY (2013) Non-invasive genetic sampling for molecular sexing and microsatellite genotyping of Hyacinth Macaw (Anodorhynchus hyacinthinus). Genet Mol Biol 36:129133.

Raymond M and Rousset F (1995) GENEPOP: Population genetics software for exact tests and ecumenicism. J. Hered 86:248-249.

Sambrook J, Russel D and Sambrook J (2001) Molecular Cloning: A Laboratory Manual. Cold Spring Harbor Laboratories, Cold Spring Harbor, New York.

Santos DO, Moreira LR, Tonhati H and Caparroz R (2012) Isolation and characterization of ten novel microsatellite loci in the Red-winged Tinamou (Rhynchotus rufescens, Tinamiformes, Aves) and cross-amplification in other tinamous. Mol Biol Rep 39:4837-4840.
Schuelke M (2000) An economic method for the fluorescent labeling of PCR fragments. Nat Biotech 18:233-234.

Segelbacher G (2002) Noninvasive genetic analysis in birds: Testing reliability of feather samples. Mol Ecol Notes 2:367-369.

Taberlet P, Griffin S, Goossens B, Questiau S, Manceau V, Escaravage N, Waits LP and Bouvet J (1996) Reliable genotyping of samples with very low DNA quantities using PCR. Nucleic Acids Res 24:3189-3194.

Temnykh S, DeClerck G, Lukashova A, Lipovich L, Cartinhour S and McCouch S (2001) Computational and experimental analysis of microsatellites in rice (Oryza sativa L.): Frequency, length variation, transposon associations, and genetic marker potential. Genome Res 11:1441-1452.

Trimbos KB, Broekman J, Kentie R, Musters CJM and de Snoo GR (2009) Using eggshell membranes as a DNA source for population genetic research. J Ornithol 150:915-920.

Untergasser A, Nijveen H, Rao X, Bisseling T, Geurts R and Leunissen JAM (2007) Primer3Plus, an enhanced web interface to Primer3. Nucleic Acids Res 35:W71-W74.

Van Oosterhout C, Hutchinson WF, Wills DPM and Shipley P (2004) Micro-checker: Software for identifying and correcting genotyping errors in microsatellite data. Mol Ecol Notes 4:535-538.

Vilaça ST, Redondo RAF, Lins LV and Santos FR (2012) Remaining genetic diversity in Brazilian Merganser (Mergus octosetaceus). Conserv Genet 13:293-298.

Vynne C, Baker MR, Breuer ZK and Wasser SK (2012) Factors influencing degradation of DNA and hormones in maned wolf scat. Anim Conserv 15:184-194.

Waits LP and Paetkau D (2005) Nonivasive genetic sampling tools for wildlife biologists: A review of applications and recommendations for accurate data collection. J Wildlife Manage 69:1419-1433.

Wultsch C, Waits LP and Kelly MJ (2014) Noninvasive individual and species identification of jaguars (Panthera onca), pumas (Puma concolor) and ocelots (Leopardus pardalis) in Belize, Central America, using cross-species microsatellites and faecal DNA. Mol Ecol Resour 14:1171-1182.

\section{Internet Resources}

BirdLife International (2015). Mergus octosetaceus. The IUCN Red List of Threatened Species, http://www.birdlife.org/datazone/species/factsheet/226804 82 (accessed 28 January, 2016).

\section{Supplementary Material}

The following online material is available for this article: Table S1 - The 27 loci tested for amplification in this study.

Associate Editor: Louis Bernard Klaczko

License information: This is an open-access article distributed under the terms of the Creative Commons Attribution License (type CC-BY), which permits unrestricted use, distribution and reproduction in any medium, provided the original article is properly cited. 